\title{
Drug prescribing by GPs in Wales and in England
}

\author{
DEE A. JONES, P. M. SWEETNAM, AND P. C. ELWOOD \\ From the MRC Epidemiology Unit, Cardiff
}

SUMmARY There is a large excess in prescribing costs by GPs in Wales compared with England. This excess amounts to about $30 \%$, equivalent at present to over $£ 11 \mathrm{~m}$ a year. The pattern of drug prescribing by GPs and of patient consultation was studied in random samples of electors in Cardiff and in Bristol. Overall, more subjects in Cardiff had received prescriptions, and the average number of scripts for each person was higher than in England in the same period. The pattern for consultations was similar. For both prescriptions and consultations the rates were higher in Wales and the difference from those in England seemed to be greater for women than for men. There was no consistent difference between the two cities in the proportions of those who had consulted who received a script, nor was there any evidence that subjects in Cardiff received more prescriptions without a consultation. In both cities similar proportions of subjects bought drugs from chemists without a prescription.

In England 293 million items were prescribed in 1976. ${ }^{1}$ This represents, on average, about $6 \cdot 4$ items a person a year. These items cost, on average, about $£ 10$ a person a year, or a total for England of $£ 451 \mathrm{~m}$. Prescribing costs in Wales have been consistently higher over the years than would be expected, by about $30 \%$. Each person on the National Health Service list in Wales received on average 8.4 items a year, at an average cost of $£ 13$ a person a year. ${ }^{2}$ The major contribution to the higher costs in Wales appears to be the number of prescriptions issued. The number of items on each prescription form, and the cost of each item, is only marginally higher in Wales than in England, each by about 2-3\%. The excess in Wales appears to apply to all drugs; for example, in 1974 , for 14 of the 16 therapeutic groups used in the DHSS reports, the average Welsh rate of prescriptions was higher than the highest of the English regional health authorities. ${ }^{3}$ Table 1 shows, for one month, average costs, etc., in England and in Wales together with average costs in two cities, Bristol and Cardiff.

There are several possible explanations for an excess in prescribing costs in Wales. The proportion of subjects in the community who become ill, or who perceive themselves as ill, could be greater than in England. On the other hand, these proportions could be the same, but the relative numbers who treat themselves, perhaps by the direct purchase of medicaments, could be greater in England than in Wales. Of those who perceive themselves as ill, the
Table 1 Details of prescribing costs in England and in Wales (and in Bristol and Cardiff*) in January, 1976

\begin{tabular}{lccc}
\hline & $\begin{array}{l}\text { ENGLAND } \\
(\text { Bristol) }\end{array}$ & $\begin{array}{l}\text { WALES } \\
\text { (Cardiff*) }\end{array}$ & $\begin{array}{l}\text { EXCESS IN } \\
\text { WALES } \\
\text { (Excess in } \\
\text { Cardiff) }\end{array}$ \\
\hline $\begin{array}{l}\text { ENCASHED } \\
\text { Prescription } \\
\text { forms per person }\end{array}$ & 0.34 & 0.42 & $22 \%$ \\
$\begin{array}{l}\text { ITEMS } \\
\text { per prescription } \\
\text { form }\end{array}$ & $10.34)$ & $(0.38)$ & $(12 \%)$ \\
$\begin{array}{l}\text { COST } \\
\text { per } \\
\text { item }\end{array}$ & $(1.58)$ & 1.66 & $3 \%$ \\
$\begin{array}{l}\text { COST } \\
\text { per } \\
\text { person }\end{array}$ & $139 p$ & $1.63)$ & $(3 \%)$ \\
\hline
\end{tabular}

* Available data all relate to the county of South Glamorgan, of which Cardiff constitutes the greater part.

proportion who consult a doctor could be higher in Wales, and of those who do consult, a higher proportion in Wales may receive a prescription from their doctors.

This study sought to answer some of these questions by examining the consultation and prescribing rates by age and sex in random population samples in an English and in a Welsh city. For reasons of convenience Bristol and Cardiff were chosen. These two cities differ substantially in prescribing costs, though not as much as England and 
Wales do (Table 1). On the other hand they appear to have a similar social class structure. The Office of Population Censuses and Surveys, in a recent classification of local authority areas by social class factors, places both cities in the same family, ${ }^{4}$ and West and Lowe calculated a socioeconomic score of 101 for Bristol and 105 for Cardiff using Moser and Scott's socioeconomic index. ${ }^{5}$

\section{Method}

Random samples of 1000 subjects were chosen from the electoral rolls for Cardiff and for Bristol. Each subject was sent a postal questionnaire requesting information about his or her consultations with a GP during the previous four weeks, whether at a surgery, at home, or by telephone. Details were sought of prescriptions, which had been received during the past four weeks, the total number of prescriptions received during the past three months, and medications purchased without a prescription. Information was obtained on the sex, age, and occupation of each respondent. Two postal reminders were sent and home visits were made to non-responders.

A linear model was fitted to the data to examine the effects of sex, age, area, and their interactions, after proportions had been logistically transformed. Estimates of statistical significance were based on this and what follows takes account of these.

\section{Results}

Table 2 shows the sample drawn and the reasons for non-response. Table 3 shows the sex and age distributions of the 1591 subjects who responded.

Table 4 summarises the data relating to the receipt of a prescription during the previous four weeks. Thirty-two per cent of Cardiff subjects had received a prescription, compared with $27 \%$ in Bristol. The excess in Cardiff $(18 \%)$ is approximately what would

Table 2 The sample drawn and the reasons for non-response

\begin{tabular}{lcccc}
\hline & \multicolumn{2}{c}{$B R I S T O L$} & \multicolumn{2}{c}{ CARDIFF } \\
\hline $\begin{array}{l}\text { ORIGINAL SAMPLE } \\
\text { Ineligible }\end{array} \quad$ 1000 & & & 1000 \\
$\quad \begin{array}{l}\text { Deceased } \\
\text { Moved away }\end{array}$ & 10 & & 19 & \\
& 99 & & 70 & \\
ELIGIBLE SAMPLE & & 891 & & 911 \\
$\begin{array}{l}\text { Not included } \\
\quad \text { Not contacted }\end{array}$ & 53 & & 71 & \\
$\quad$ Refused & 40 & & 32 & \\
$\quad$ Too ill & 5 & & 10 & \\
$\quad$ RESPONDENTS & & 793 & & 798 \\
Response rate & & $89 \%$ & & $88 \%$ \\
\hline
\end{tabular}

Table 3 Age and sex distribution of respondents

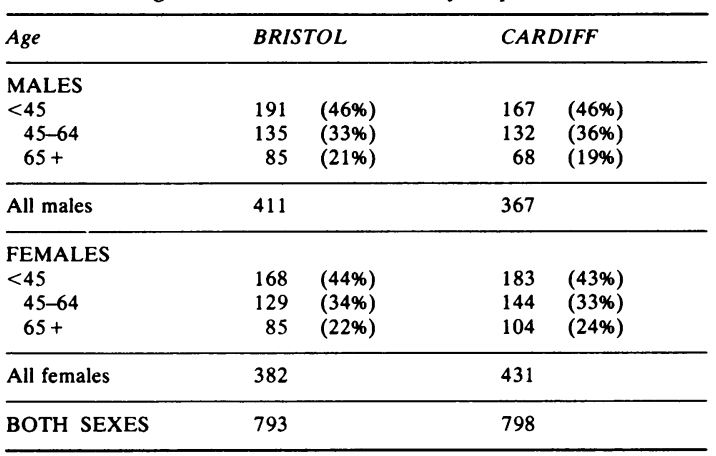

be expected from the routinely collected information shown in Table 1. The excess appears to be largely confined to women, although in fact the intercity difference does not differ significantly $(P<0.05)$ between the two sexes. The data in this and in other Tables show the age and sex trends which would be expected, ${ }^{6}$ namely, prescribing rates are higher for women than for men, and for older subjects than foo younger ones.

Table 5, which summarises data relating t\$ prescriptions received over a three-month perio $\vec{F}$ confirms the trends demonstrated in Table 4. Th8 excess in Cardiff is about $20 \%$ and women appear tQ $\overparen{Q}$ contribute most of this, but again the intercit $\overrightarrow{0}$ differences are statistically homogeneous in the two sexes.

Most prescriptions are obtained by direct consultation with a GP. Table 6 therefore sets out the numbers of subjects who had consulted during the four weeks before they were questioned. The overall rates are about $20 \%$ higher in Cardiff than in Bristol and women appear to contribute most of this excess, although again the data are not conclusive on this point.

Of those who had consulted a GP, the proportion who had received a prescription was similar in Cardiff and Bristol for both sexes (men $81 \%$ and $85 \%$, women $88 \%$ and $82 \%$ ). Overall, there is a fairly consistent age trend: that is, older patients who consult are rather more likely to get a prescription form than are younger patients.

In order to investigate the hypothesis that self-medication is an alternative to obtaining prescriptions, and that Bristol subjects purchase medicaments directly from the chemist more often than Cardiff subjects, we studied the pattern of self-medication among those who had and those who had not received a script in the four-week period. Of those who had not received a prescription, the proportion who had purchased medicaments directly 
Table 4 Subjects who had received a prescription during the previous four weeks

\begin{tabular}{|c|c|c|c|c|c|c|}
\hline & \multicolumn{3}{|c|}{ BRISTOL } & \multicolumn{3}{|c|}{$C A R D I F F$} \\
\hline & \multirow{2}{*}{$\begin{array}{l}\begin{array}{l}\text { No. of } \\
\text { subjects }\end{array} \\
\\
191 \\
135 \\
85 \\
411\end{array}$} & \multicolumn{2}{|c|}{$\begin{array}{l}\text { No. (\%) with } \\
\text { prescription }\end{array}$} & $\begin{array}{l}\text { No. of } \\
\text { subjects }\end{array}$ & \multicolumn{2}{|c|}{$\begin{array}{l}\text { No. (\%) with } \\
\text { prescription }\end{array}$} \\
\hline $\begin{array}{c}<45 \\
45-64 \\
65+ \\
\text { All males }\end{array}$ & & $\begin{array}{l}27 \\
39 \\
30 \\
96\end{array}$ & $\begin{array}{l}(14 \%) \\
(29 \%) \\
(35 \%) \\
(23 \%)\end{array}$ & $\begin{array}{r}167 \\
132 \\
68 \\
367\end{array}$ & $\begin{array}{l}27 \\
31 \\
29 \\
87\end{array}$ & $\begin{array}{l}(16 \%) \\
(23 \%) \\
(43 \%) \\
(24 \%)\end{array}$ \\
\hline $\begin{array}{l}\text { FEMALES } \\
<45 \\
45-64 \\
65+ \\
\text { All females }\end{array}$ & $\begin{array}{r}168 \\
129 \\
85 \\
382\end{array}$ & $\begin{array}{r}35 \\
44 \\
37 \\
116\end{array}$ & $\begin{array}{l}(21 \%) \\
(34 \%) \\
(44 \%) \\
(30 \%)\end{array}$ & $\begin{array}{l}183 \\
144 \\
104 \\
431\end{array}$ & $\begin{array}{r}53 \\
57 \\
55 \\
165\end{array}$ & $\begin{array}{l}(29 \%) \\
(40 \%) \\
(53 \%) \\
(39 \%)\end{array}$ \\
\hline BOTH SEXES & 793 & 212 & (27\%) & 798 & 252 & (32\%) \\
\hline
\end{tabular}

Table 5 Percentage of subjects who had received three or more prescriptions, and the average number of prescriptions received during the three-month period before they were questioned

\begin{tabular}{|c|c|c|c|c|c|c|c|c|}
\hline \multirow{3}{*}{$\frac{\text { Age }}{\text { MALES }}$} & \multicolumn{4}{|c|}{ BRISTOL } & \multicolumn{4}{|c|}{ CARDIFF } \\
\hline & \multirow{2}{*}{$\begin{array}{l}\begin{array}{l}\text { No. of } \\
\text { subjects }\end{array} \\
\end{array}$} & \multirow{3}{*}{$\begin{array}{l}\begin{array}{l}\text { Three or more } \\
\text { prescriptions }\end{array} \\
3 \%\end{array}$} & \multicolumn{2}{|c|}{$\begin{array}{l}\text { Average no. of } \\
\text { prescriptions } \\
\text { per person* }\end{array}$} & \multirow{2}{*}{$\begin{array}{l}\text { No. of } \\
\text { subjects }\end{array}$} & \multirow{2}{*}{$\begin{array}{l}\text { Three or more } \\
\text { prescriptions }\end{array}$} & \multicolumn{2}{|c|}{$\begin{array}{l}\text { Average no. of } \\
\text { prescriptions } \\
\text { per person * }\end{array}$} \\
\hline & & & & & & & & \\
\hline$<45$ & 191 & & 0.4 & $(0.9)$ & 167 & $6 \%$ & 0.5 & $(1 \cdot 3)$ \\
\hline $45-64$ & 135 & $12 \%$ & 0.7 & $(1.2)$ & 132 & $11 \%$ & 0.7 & $(1.0)$ \\
\hline $65+$ & 85 & $21 \%$ & $1 \cdot 2$ & $(1 \cdot 5)$ & 68 & $25 \%$ & 1.7 & $(2.7)$ \\
\hline All males & 411 & $10 \%$ & 0.7 & $(1 \cdot 2)$ & 367 & $11 \%$ & $0 \cdot 8$ & $(1 \cdot 6)$ \\
\hline \multicolumn{9}{|l|}{ FEMALES } \\
\hline$<45$ & 168 & $7 \%$ & 0.8 & $(1 \cdot 1)$ & 183 & $12 \%$ & 0.9 & $(1 \cdot 2)$ \\
\hline $45-64$ & 129 & $20 \%$ & $1 \cdot 1$ & $(1.4)$ & 144 & $21 \%$ & 1.3 & $(1.8)$ \\
\hline $65+$ & 85 & $26 \%$ & 1.5 & $(1.6)$ & 104 & $31 \%$ & 1.7 & $(1 \cdot 7)$ \\
\hline All females & 382 & $16 \%$ & 1.0 & $(1 \cdot 3)$ & 431 & $20 \%$ & 1.2 & $(1 \cdot 6)$ \\
\hline BOTH SEXES & 793 & $13 \%$ & 0.8 & $(1 \cdot 3)$ & 798 & $16 \%$ & 1.0 & $(1 \cdot 6)$ \\
\hline
\end{tabular}

" Standard deviations in parentheses.

Table 6 Subjects who had consulted a GP during the previous four weeks

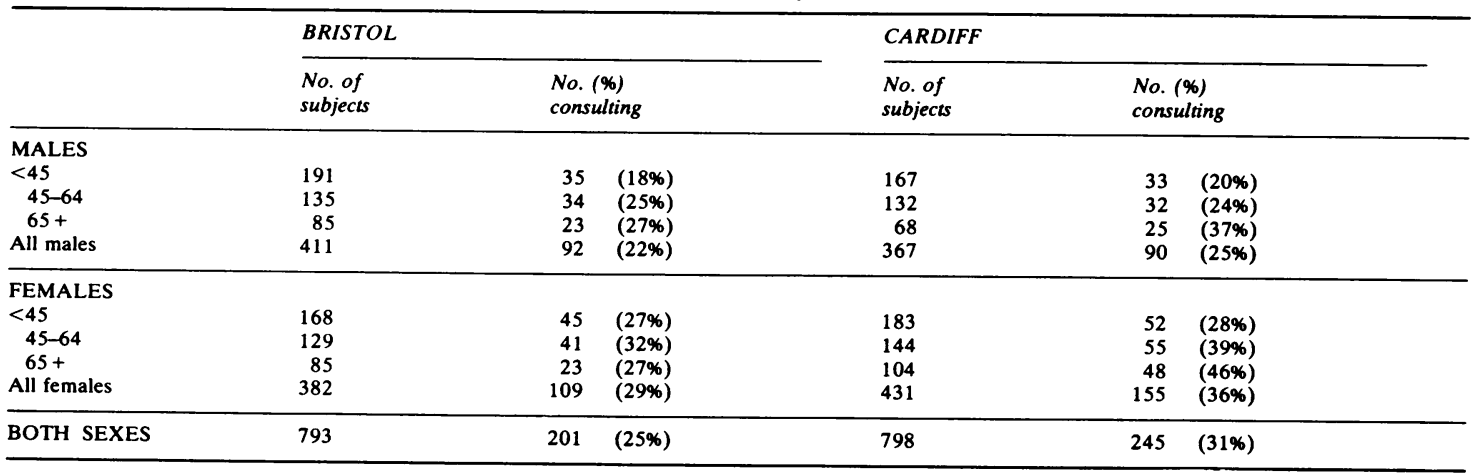


was higher among women than men and declined markedly with age in both cities, but the rates in Bristol (men 23\%, women 32\%) were almost identical to those in Cardiff (19\% and $31 \%)$.

\section{Discussion}

Prescribing rates in general practice are widely accepted as being too high, ${ }^{78}$ and it is probable that a high proportion of patients fail to take drugs as advised. ${ }^{910}$ Against this background, a $30 \%$ excess in prescribing costs in Wales compared with England is disturbing. At current prices this excess is equivalent to at least $£ 11 \mathrm{~m}$ a year.

Our study indicates fairly clearly that the excess is not generated to any appreciable extent by doctors. Substantial differences between doctors in prescribing do undoubtedly occur but overall, in Cardiff and in Bristol, there seems to be a very similar chance that a patient who consults will be given a prescription. This probability is age-related: the older the patient, the more likely it is that a prescription will be received; but in our data at any rate, there is no clear evidence that it is related to social class.

Our data confirm that prescribing rates are higher in Wales than in England and the size of the excess we detected is about the same as that shown by the routinely published data for the two areas included in our study. ${ }^{12}$ Excess prescribing rates could arise from 'repeat' prescriptions and a high overall rate could be generated by excessive demands from a small number of patients. Our data provide no evidence that the Welsh excess arises from such a subgroup because the proportions of subjects in the two cities who received multiple prescriptions (Table 5) show the same sort of proportional difference as the other measures of prescribing which we examined.

A second possible way in which higher costs could be generated is if all patients made higher demands. Our data suggest that this does occur in Wales, and that it may occur to a greater extent among women than among men.

There is one very important aspect of the higher prescribing costs in Wales on which our study gives no evidence. This is the extent to which excess demands arise from a higher burden of disease. Mortality rates for most conditions are higher in Wales than in England. Thus, the standardised mortality ratio (SMR) for all causes of death in Wales is $\mathbf{1 0 9}$ for men and $\mathbf{1 0 5}$ for women, but only $\mathbf{9 9}$ for both men and women in England alone. ${ }^{11}$ For arteriosclerotic heart disease and for respiratory disease, these differences are on the whole rather larger. It is impossible to translate differences in SMRs into likely differences in consultation rates or prescribing rates ${ }^{12}$ although, however effective the treatment, diseases which lead to a higher mortality rate are likely to generate higher prescribing costs. Conditions such as respiratory disease, which are chronic and for which drug therapy is available, could therefore lead to an excess in treatment costs which is much larger than might at first be suggested by mortality data.

Some of the excess prescribing costs in Wales could be explained by higher morbidity rates in Wales. However, an excess arising in this way would be likely to lead to an excess in prescribing rates in men and in women very similar to the Welsh excess in mortality; and probably the Welsh excess in morbidity occurs in both sexes. The most interesting outcome in our study is the evidence which, although not statistically convincing, suggests that the Welsh excess is $\vec{\circ}$ generated largely by women patients. This was not expected and, if it is true, it is clearly relevant to some of the possible ways in which the overall excess in prescribing may arise in Wales. On the other hand, we know of no evidence which could explain a sex disparity and although Beresford and heto colleagues ${ }^{13}$ identified a number of factors relevant $t \mathrm{Q}$ consultation rates among women, there is no obvious

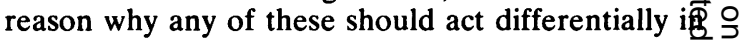
Wales and in England.

The disparity between the sexes in the two cities although we cannot be sure from our data that it real, might suggest that the excess prescribing costs 1 Wales arise to a substantial extent because of highe demands and not solely because of a greater burden of disease. However, further studies will be required to examine again the prescribing rates in the two sexes separately, and to sort out more clearly the contribution to the Welsh 'excess' which can be attributed to disease, and that which can be attributed to 'behavioural' differences.

We thank all those who helped in this study, in particular Mrs. Carole Eedy and Mr. Tom Benjamin, who visited the non-responders in their homes.

Reprints from Dee A. Jones, Research Team for the Care of the Elderly, Welsh National School of 0 Medicine, St. David's Hospital, Cowbridge Road, Cardiff CF1 9TZ.

\section{References}

${ }^{1}$ Department of Health and Social Security. Health and personal social services statistics for England. London: HMSO, 1977.

${ }^{2}$ Welsh Office. Health and personal social services statistics for Wales. London: HMSO, 1977. 
${ }^{3}$ The Prescription Pricing Authority. Statistical data relating to the total prescriptions dispensed by chemist contractors during 1974. London: HMSO, 1975.

- Office of Population Censuses and Surveys. Socioeconomic Classification of Local Authority Areas. Studies on Medical and Population Subjects No. 35. London: OPCS, 1979.

${ }^{5}$ West RR, Lowe CR. Mortality from ischaemic heart disease. Int J Epidemiol 1976; 5: 195-201.

${ }^{6}$ Skegg DCG, Doll R, Perry J. Use of medicines in general practice. Br Med J 1977; i: 1561-63.

${ }^{7}$ Bignall JC. Prescribing in general practice. Lancet 1976; 2: 371.

${ }^{8}$ Taylor RJ. General Practitioner prescribing. J $R$ Coll Gen Pract 1977; 27: 79-82.
${ }^{9}$ Haggerty RJ, Roghman KJ. Noncompliance and self-medication. Two neglected aspects of pediatric pharmacology. Pediatr Clin North Am 1972; 19: 101-5.

${ }^{10}$ Lloyd G. Compliance with medical treatment. A review. Update 1976; 227-9.

${ }^{11}$ Office of Population Censuses and Surveys. Decennial Supplement No. 3: Area Mortality. London: OPCS, 1979.

${ }^{12}$ Beresford SAA, Waller JJ, Banks MH, Wale CJ. Why do women consult doctors? Social factors and the use of the general practitioner. Br J Prev Soc Med 1977; 31: 220-6. 